\title{
Impact of Human Capital on Entrepreneurial Earnings: Employing Parametric and Nonparametric Methods
}

\author{
Hatice Karahan \\ TUBITAK, The Scientific and Technological Research Council of Turkey \\ hatice.karahan@tubitak.gov.tr
}

\begin{abstract}
Economics literature provides ample evidence regarding the important positive effect of human capital on earnings. However, the self-employed have been consistently omitted in such studies. To fill this gap, I examine the effect of human capital on entrepreneurial earnings using National Survey of College Graduates dataset. To estimate the coefficients on income levels, I take advantage of three different econometric methods, namely OLS, Heckit and matching estimators. Regression results on men show that having higher education brings more success in terms of self-employment earnings. Evidence shows that men do better when they are self-employed whereas women are better off when they are wage workers. The most lucrative majors for male entrepreneurs are architecture, math, physics, chemistry and most fields of engineering. Women entrepreneurs who enjoy higher earnings are mostly majored in architecture, medicine, law, psychology and counseling. However, no particular education level is found to contribute to female entrepreneurial earnings.
\end{abstract}

Keywords: Self-Employment, Entrepreneurship, Income, Education, Human Capital

\section{Introduction}

Most of the studies that focus on wage and salary workers show that human capital is the most significant determinant of their earnings. The level of schooling and the field of the study are both found to affect earnings of employees considerably. However, this important factor has been surprisingly ignored in studies examining "entrepreneurs". To date, no study has analyzed the impact of educational degrees and majors on the success of the self-employed. This could be partly because of the data limitations regarding majors. Neither the proportion of self-employed people in population nor their contribution to the economy is trivial. That is why I think that the examination of education in this context is significant and would contribute to the literature on self-employment. Therefore, this paper focuses on the role of human capital in entrepreneurial success. To conduct this study I take advantage of the Decennial Census conducted by the Bureau of Census and The National Survey of College Graduates (NSCG) dataset. This dataset supplies detailed information on the degrees and majors as well as demographic characteristics of 149,000 Americans with a Bachelor's degree or higher. Nearly 140 majors are available in the data. Approximately 14,000 of the respondents report self-employment earnings. This dataset helps me tackle the issue of data limitation regarding human capital. The paper proceeds as follows: Section II provides a brief literature review on entrepreneurial success and survival. Section III presents the data source that is used in this study along with some descriptive statistics. Section IV discusses empirical strategy and basic results. Conclusions and directions for future research are presented in Section V.

\section{Literature Review}

To my knowledge, there are only a few empirical studies which examine entrepreneurship in terms of earnings and success. However, as noted earlier, almost none of them concentrate on the educational aspect. Most of the studies which analyzed entrepreneurial income focused on the comparison of the distribution of earnings for the self-employed and employees. Whereas some of these studies such as Rees \& Shah (1996), Borjas \& Bronars (1989) and Gill (1988) found out that mean earnings for the two groups are similar, Hamilton (2000) concludes that the earnings of the self-employed are lower than those of employees at the 25th and 50th percentile of their respective wage distributions. A recent study by Moore (2004) which uses alternative measures for self-employment income shows that it is not true that median entrepreneurial income is significantly lower than employee wages. It should be also noted that the regression results of this study reveals a higher return to education and tenure for the selfemployed than employees. In a seminal paper, Evans \& Jovanovic (1989) analyze the major determinants of entrepreneurial earnings and the process of transition to self-employment over the life cycle. Their 
estimates show that the probability of switching into self-employment is independent of age as well as total labor market experience. They also find out that the returns to education are somewhat higher in self-employment than in wage work. The only paper which directly examines the relationship between education and self-employment success is Kangasharju \& Pekkalas (2001). They are focused on the periods of economic fluctuations in Finland and their results suggest that higher education has a strong negative effect on the exit probability in the recession period. However, their focus was only on educational levels so a detailed analysis regarding majors is still needed. My main contribution to the literature with this paper is the inclusion of detailed variables on human capital such as majors and degrees in the examination of earnings determinants for the self-employed.

\section{Methodology}

Data and Descriptive Statistics: For the empirical analysis, I use 1990 Decennial Census conducted by the Bureau of Census and The National Survey of College Graduates (NSCG) dataset which provide detailed information on 149,000 Americans with a Bachelor's degree or higher. The data elicit information on the last three degrees completed by the individuals along with the field of study earned. Nearly 140 majors are available in the data. The self-employed group is composed of those who respond to the "class of worker" question as either "Self-employed, incorporated" or "Self-employed, not incorporated" as of 1990. After dropping those who work without pay or those with imputed observations, the number of self-employed men and women turns out to be around 13,000. The analyses are performed separately for male and female respondents. In terms of human capital I am mainly interested in the role of highest majors and degrees the individuals have earned. Table 1 shows the means of earnings for wage employees and the self-employed based on educational degrees. Regardless of degree, self-employed men seem to enjoy higher earnings than male employees. However, it is apparent that once they have a higher degree, namely Professional or PhD degree, they do significantly better. Whereas women with a Bachelor's or Master's degree are better off when they are wage employees, it is quite the opposite for those with a higher degree. This difference of income is especially quite conspicuous within the group with a Professional degree. These statistics might be interpreted as the likely contribution of higher education levels to self-employment earnings.

Table 1: Means of Income by the Highest Degree and Self-employment status (in dollars), National Survey of College Graduates (NSCG)

\section{PANEL A: Men}

\begin{tabular}{lll}
\hline Sample & Wage-Employed & Self-Employed \\
\hline Bachelors & 42055 & 50959 \\
Masters & 48294 & 60290 \\
Professional Degree & 86845 & 131637 \\
Doctorate & $57012 \quad[\mathrm{n}=54,294]$ & 98499 \\
Total & & {$[\mathrm{n}=7,385]$} \\
\hline
\end{tabular}

PANEL B: Women

\begin{tabular}{lll}
\hline Sample & Wage-Employed & Self-Employed \\
\hline Bachelors & 25471 & 26639 \\
Masters & 31226 & 27235 \\
Professional Degree & 52095 & 70695 \\
Doctorate & 39658 & 44317 \\
Total & {$[\mathrm{n}=33,729]$} & {$[\mathrm{n}=2,311]$} \\
\hline
\end{tabular}

Notes: The data are weighted to reflect sample stratification. Data include respondents only who completed the interviews. Unemployed individuals, people with "unavailable" labor class responses and those who work without pay in family business are dropped. Self-employed group is composed of those who respond to the "class of worker" question as either "Self-employed, incorporated" or "Self-employed, not incorporated" as of 1990. Imputed observations related to some variables like age, class of worker, education level, marriage, wage income, farm self-employment income and non-farm self-employment income are eliminated. In Table 2, means of earnings for each race category are presented. The figures reveal that people from all races have higher earnings when self-employed. However, the Asian male and female entrepreneurs are apparently much more successful compared to those from other races. 
Table 2: Means of Income by Race and Self-employment Status (in dollars), NSCG

PANEL A- Men

\begin{tabular}{lll}
\hline Sample & Wage-Employed & Self-Employed \\
\hline White & 48498 & 79499 \\
Black & 37221 & 61486 \\
Hispanic & 35280 & 110860 \\
Asian & 45967 & 98607 \\
\hline PANEL B- Women & & \\
\hline Sample & Wage-Employed & Self-Employed \\
\hline White & 28358 & 30409 \\
Black & 28678 & 43442 \\
Hispanic & 25826 & 28063 \\
Asian & 31192 & 53953 \\
\hline
\end{tabular}

Table 3 summarizes the means of earnings based on the highest degree earned and the broad field of study. Each panel represents the highest degree earned, separately for men and women. These thirteen fields were created by aggregating similar majors in the dataset under the same groups. Among men who hold a Bachelor's or Master's degree, the entrepreneurs who majored in Math, Education, Health, Law, Business and Arts are found to have significantly higher earnings. The mean of self-employment income is also observed to enormously surpass that of wages for all fields within the classes of Professional and PhD degrees. As for women, most majors with a Bachelor's degree do better in case of wage employment. The only fields in which female entrepreneurs are more successful are Math, Health and Physical Sciences. Statistics show a similar pattern for women with a Master's degree, too. Within this degree category, only those who majored in Physical Sciences enjoy higher earnings. In all other fields, employees seem to be better off. When it comes to women with a Professional degree one can conclude that for all fields of studies listed, the self-employed make significantly more than employees. Because there are only a few self-employed women with a PhD degree in each field category, I am not able to make a healthy comparison between the two groups of labor. However, for all the fields in which there are at least 10 entrepreneurs, self-employment earnings are observed to be higher.

Table 3: Means of Income by Highest Degree Earned and Broad Field of Study, NSCG

PANEL A- MEN

\begin{tabular}{lll}
\hline Field-Bachelor`s Degree & Wage-Employed & Self-Employed \\
\hline Mathematical Sciences & 46728 & 64521 \\
Physical Sciences & 42391 & 50493 \\
Life Sciences & 36727 & 47553 \\
Agricultural Sciences & 38694 & 39651 \\
Computer Sciences & 37856 & 39836 \\
Engineering & 47167 & 55385 \\
Engineering Technologies & 41236 & 41721 \\
Business and Economics & 44362 & 54989 \\
Health Professions & 40166 & 80849 \\
Education & 34951 & 42066 \\
Humanities and Law & 39590 & 48823 \\
Fine Arts & 31978 & 42289 \\
Field-Master`s Degree & Wage-Employed & Self-Employed \\
Mathematical Sciences & 50802 & 66168 \\
Physical Sciences & 47874 & 51085 \\
Life Sciences & 40564 & 33862 \\
Agricultural Sciences & 46986 & 65921 \\
Computer Sciences & 48049 & 64059 \\
Engineering & 56736 & 61905 \\
Engineering Technologies & 50047 & 41661 \\
Business and Economics & 55041 & 71649 \\
Health Professions & 42741 & 69333 \\
Education & 39211 & 51349 \\
Humanities and Law & 44659 & 58608 \\
Fine Arts & 35689 & 51769 \\
& & \\
& &
\end{tabular}




\begin{tabular}{|c|c|c|}
\hline Field-Professional Degree & Wage-Employed & Self-Employed \\
\hline Health Professions & 104384 & 145518 \\
\hline Education & 63933 & 121117 \\
\hline Social Sciences & 95661 & 139287 \\
\hline Humanities and Law & 75465 & 115223 \\
\hline Field-Doctorate Degree & Wage-Employed & Self-Employed \\
\hline Mathematical Sciences & 58585 & $*$ \\
\hline Physical Sciences & 61047 & 146641 \\
\hline Life Sciences & 53258 & 112065 \\
\hline Agricultural Sciences & 53188 & $*$ \\
\hline Computer Sciences & 72264 & $*$ \\
\hline Engineering & 66547 & 83617 \\
\hline Engineering Technologies & 63441 & $*$ \\
\hline Business and Economics & 62270 & 72861 \\
\hline Health Professions & 74381 & 118396 \\
\hline Education & 49463 & 86433 \\
\hline Humanities and Law & 50289 & 85924 \\
\hline Fine Arts & 48421 & $*$ \\
\hline \multicolumn{3}{|l|}{ PANEL B- WOMEN } \\
\hline Field-Bachelor`s Degree & Wage-Employed & Self-Employed \\
\hline Mathematical Sciences & 32835 & 47432 \\
\hline Physical Sciences & 28580 & 33807 \\
\hline Life Sciences & 25096 & 23995 \\
\hline Agricultural Sciences & 23467 & 17209 \\
\hline Computer Sciences & 33275 & 28287 \\
\hline Engineering & 33851 & 27660 \\
\hline Engineering Technologies & 29754 & $*$ \\
\hline Business and Economics & 27008 & 25730 \\
\hline Health Professions & 28035 & 30827 \\
\hline Education & 21868 & 21115 \\
\hline Humanities and Law & 24654 & 21680 \\
\hline Fine Arts & 21554 & 15586 \\
\hline Field-Master`s Degree & Wage-Employed & Self-Employed \\
\hline Mathematical Sciences & 38361 & 31926 \\
\hline Physical Sciences & 34400 & 40475 \\
\hline Life Sciences & 30370 & 20347 \\
\hline Agricultural Sciences & 32705 & $*$ \\
\hline Computer Sciences & 40283 & $*$ \\
\hline Engineering & 39751 & $*$ \\
\hline Business and Economics & 36531 & 24481 \\
\hline Health Professions & 32894 & 28793 \\
\hline Education & 29502 & 29059 \\
\hline Humanities and Law & 31295 & 28372 \\
\hline Fine Arts & 26423 & 18669 \\
\hline Field-Professional Degree & Wage-Employed & Self-Employed \\
\hline Health Professions & 58201 & 79992 \\
\hline Education & 38759 & 59318 \\
\hline Social Sciences & 57120 & 65815 \\
\hline Humanities and Law & 48821 & 61987 \\
\hline Field-Doctorate Degree & Wage-Employed & Self-Employed \\
\hline Mathematical Sciences & 50956 & $*$ \\
\hline Physical Sciences & 41010 & $*$ \\
\hline Life Sciences & 38141 & $*$ \\
\hline Engineering & 44434 & $*$ \\
\hline Health Professions & 38652 & $*$ \\
\hline Education & 39617 & 42234 \\
\hline Humanities and Law & 40046 & 48550 \\
\hline Fine Arts & 40836 & 45379 \\
\hline
\end{tabular}

* Indicates fewer than 10 respondents 


\section{Results}

The primary purpose of this paper is to analyze the effects of human capital on entrepreneurial earnings. For this purpose, I have two main regressions, one for the self-employment earnings and the other one for the probability of being self-employed.

1) $Y_{1}=X \beta+\varepsilon_{1}$ if $Y_{2}=1$

$=0 \quad$ otherwise

2) $Y_{2}=x b+\varepsilon_{2}$

Equation (1) represents the "earnings" regression run by OLS. The dependent variable, $\mathrm{Y}_{1}$ in this model is a logarithmic function of the earnings of self-employed people and is defined as

3) $Y_{1}=\ln (y+19990)$ where y represents self-employment earnings.

The reason behind this transformation is that the self-employed sample, unlike employees, has zero and negative earnings which makes the log value infinite or undefined. Because the smallest negative value in the sample is -19989 , I added 19990 to all observations to make them at least 1 . The independent variables vector $\mathrm{X}$ includes the highest majors and degrees earned, age, square of age, race, marital status, education of father and mother and a dummy for whether the individual has grown up in a rural area. In addition, eight divisions of USA are controlled in this regression. Business administration which is the largest group within the "highest major" variable is excluded to avoid the dummy variable trap. The reference group with respect to "race" is whites. The academic degrees that the respondents have are classified into six groups as follows: Bachelor's, Master's (MA), Doctor of Philosophy (PhD), Medical Doctor (MD), Juris Doctor (JD) and the Other Professional degrees. Bachelor's degree is excluded in the analysis. Equations are separately estimated for men and women. Equation (2) is basically a Probit regression in which the decision to be self-employed $\left(\mathrm{Y}_{2}\right)$ is equal to 1 if the individual reported to have self-employment earnings in 1990 or equal to 0 if not. The exogenous variables, $\mathrm{x}$ in this model are the same as in the OLS equation except for the inclusion of the variable which represents the number of kids an individual has under 18 years old. A major drawback of this analysis is the identification problem of self-employed people. As can be seen in Equation (1), $Y_{1}$ is defined depending on the value of $Y_{2}$. So, selfemployment earnings are only observed for a restricted sample, namely the self-employed. This means that an OLS regression of $\mathrm{Y}_{1}$ on $\mathrm{X}$ leads to inconsistent estimation of $\beta$. One cannot ignore this selfselection problem. In order to solve this issue, an exclusion restriction is required. I went through the variables in the dataset thoroughly and the most suitable candidate I could find for this variable was the number of kids. To get consistent estimates, I use this exclusion restriction employing a Heckit procedure. The first step for this procedure is basically obtaining the estimated inverse Mills ratios (EIMR) using the Probit regression. In the second step, an OLS regression is run on the exogenous variables and the EIMR. One important point is that the number of kids is used as an independent variable in the Probit analysis but not in the OLS. We can express this procedure in equations as follows:

- $\quad$ Step 1: Run Equation (2) to obtain estimates of $b / \sigma_{2}$

- Step 2: Use these estimates to construct the $\operatorname{EIMR}=\left[\varphi\left(\mathrm{xb} / \sigma_{2}\right)\right] /\left[\Phi\left(\mathrm{xb} / \sigma_{2}\right)\right]$ where $\varphi($.$) is the$ standard normal density and $\Phi($.$) is its cumulative distribution function.$

- $\quad$ Step 3: Run OLS as follows: $\mathrm{Y}_{1}=\mathrm{X} \beta+\mathrm{EIMR}^{*} \alpha$ where $\alpha$ is the coefficient on EIMR.

Table 4 shows the exogenous variables which have significant effects on self-employment earnings based on the Heckit and OLS regression results. Majors with fewer than 30 respondents are not included in the table. I mainly focus on the Heckit findings but in the table I report the OLS estimates too in order to reveal how the two techniques lead to different conclusions. It should be noted that only the statistically significant coefficients are exhibited. Evidence from Heckit shows that having a degree in most engineering fields and some physical sciences like math, physics, and chemistry have highly significant impacts on earnings of self-employed men. Interestingly, while the OLS results report positive effects of a medical degree, the coefficient from the Heckit procedure proves it wrong. For the female self-employed, architecture, medicine, physical therapy, law, clinical psychology and counseling are the most lucrative majors. As can be observed from the table, most of the majors that are found to have significant effects on self-employment earnings by the Heckit do not show up among the significant OLS estimates. On the other hand, some significant estimates by OLS turn out to be insignificant when I employ the Heckit technique. This shows that in sample selection models, OLS yields inconsistent estimates and leads to quite different conclusions. Whereas age has a negative impact on male earnings it seems to have a positive one for the female. Female self-employment earnings are observed to be increasing with age at a 
declining rate. Marriage and being grown up in a rural area do not turn out to have any effect on selfemployment income. It is interesting that the Heckit estimation implies that the black male entrepreneurs earn more. In addition, self-employed men with a Medical Doctor degree appear to enjoy higher earnings compared to those with a Bachelor's degree. Among women, Master's, PhD and other professional degree holders seem to earn less. Being an Asian woman affects self-employment earnings adversely.

Table 4: Heckit and OLS analyses of self-employment earnings

\section{PANEL A-MALE}

\begin{tabular}{|c|c|c|}
\hline Variable & Heckit & OLS \\
\hline \multicolumn{3}{|l|}{ MAJORS: } \\
\hline Agricultural Business & & $0.305(0.135)$ \\
\hline Agricultural Science & & $0.409(0.142)$ \\
\hline Architecture & & $0.222(0.063)$ \\
\hline Accounting & & $0.295(0.054)$ \\
\hline Secondary School Teacher Education & & $0.264(0.133)$ \\
\hline Biochemistry & $0.502(0.251)$ & \\
\hline Business Economics & $-0.250(0.123)$ & \\
\hline Market Research & $-0.459(0.199)$ & \\
\hline Computer Science & $0.317(0.123)$ & \\
\hline Educational Counseling & $0.484(0.252)$ & \\
\hline Architectural Engineering & & $0.281(0.098)$ \\
\hline Chemical Engineering & $0.546(0.197)$ & \\
\hline Civil Engineering & $0.228(0.079)$ & \\
\hline Computer Engineering & $0.519(0.219)$ & \\
\hline Electrical Engineering & $0.567(0.132)$ & \\
\hline Engineering Sciences & $0.497(0.233)$ & \\
\hline General Engineering & $0.498(0.256)$ & \\
\hline Mechanical Engineering & $0.483(0.099)$ & $0.203(0.677)$ \\
\hline Electrical Technologies & $0.481(0.186)$ & \\
\hline Mechanical Technologies & $0.367(0.183)$ & \\
\hline Foreign Languages & $0.452(0.180)$ & \\
\hline Health Technologies & $0.802(0.381)$ & \\
\hline Medical Preparation & & $0.336(0.134)$ \\
\hline Medicine & $-0.478(0.225)$ & $0.328(0.098)$ \\
\hline Health Science & & $0.248(0.119)$ \\
\hline Nursing & $0.867(0.367)$ & \\
\hline Law & & $0.429(0.121)$ \\
\hline Applied Math & $0.627(0.226)$ & \\
\hline Math & $0.778(0.145)$ & $0.423(0.111)$ \\
\hline Philosophy \& Religion & $0.332(0.125)$ & \\
\hline Chemistry & $0.718(0.147)$ & $0.315(0.105)$ \\
\hline Physics & $0.819(0.192)$ & $0.301(0.143)$ \\
\hline Clinical Psychology & & $0.499(0.102)$ \\
\hline Counseling & & $0.328(0.120)$ \\
\hline Fine Arts & $-0.255(0.125)$ & \\
\hline \multicolumn{3}{|l|}{ OTHER: } \\
\hline MA degree & & $-0.189(0.083)$ \\
\hline MD degree & $0.470(0.163)$ & \\
\hline Age & $-0.032(0.014)$ & $0.016(0.008)$ \\
\hline Age Squared & & $-0.00019(0.00)$ \\
\hline Asian & & $-0.106(0.033)$ \\
\hline Black & $0.268(0.091)$ & \\
\hline East North Central region & & $-0.129(0.031)$ \\
\hline West North Central region & & $-0.132(0.042)$ \\
\hline South Atlantic region & & $-0.174(0.029)$ \\
\hline West South Central region & & $-0.093(0.035)$ \\
\hline Mountain region & & $-0.157(0.041)$ \\
\hline
\end{tabular}


PANEL B - FEMALE

\begin{tabular}{lll}
\hline Variable & Heckit & OLS \\
\hline MAJORS: & $0.281(0.160)$ & \\
Architecture & $0.381(0.201)$ & \\
Medicine & $0.394(0.135)$ & \\
Physical Therapy & $0.989(0.381)$ & $1.042(0.386)$ \\
Law & $0.521(0.163)$ & $0.219(0.101)$ \\
Clinical Psychology & $0.242(0.119)$ & \\
Counseling & $0.597(0.245)$ & \\
General Psychology & $0.279(0.094)$ & $-0.219(0.095)$ \\
Social Work & & \\
Music & $-0.406(0.129)$ & $-0.258(0.104)$ \\
OTHER: & $-0.419(0.137)$ & $-0.243(0.105)$ \\
MA degree & $-0.793(0.401)$ & $-0.957(0.397)$ \\
PhD degree & $0.063(0.016)$ & $0.035(0.009)$ \\
Other Professional Degree & $-0.0006(0.00)$ & $-0.0004(0.0)$ \\
Age & & $0.132(0.063)$ \\
Age Squared & & $-0.065(0.026)$ \\
Black & $-0.131(0.054)$ & \\
Married & $-0.146(0.059)$ & \\
Asian & $-0.209(0.049)$ & $-0.145(0.039)$ \\
New England Region & $-0.281(0.069)$ & $-0.203(0.057)$ \\
East North Central region & $-0.157(0.047)$ & $-0.101(0.039)$ \\
West North Central region & $-0.168(0.086)$ & $-0.114(0.048)$ \\
South Atlantic region & $-0.164(0.054)$ & \\
East South Central region & & \\
West South Central region & & \\
\hline Notesi Only the variables with signif & \\
\hline
\end{tabular}

Notes: Only the variables with significant effects are represented. Majors with fewer than 30 respondents are not included in the tables.

Due to the fact that the exclusion restriction used in the Heckit analysis is not quite satisfactory although it is the most suitable one in the dataset available, I also estimated the effects using matching estimators. The advantage of using a matching method comes from its nonparametric nature. The basic idea behind a matching estimator is to get the best estimate of the counterfactual untreated outcome for an individual in the treatment group which is the outcome of the individuals most similar to him in the control group. Specifically, matching uses an observation drawn from the control group to create an estimate of the counterfactual for each observation in the treatment group. In this analysis, the treated group is considered the self-employed and the untreated group is the wage workers. Hence, in order to see the effects of being self-employed on the level of earnings, potential wage earnings of the self-employed individuals need to be calculated. In other words, wage income will be used a measure of what selfemployed people would have received had they not been self-employed. The first matching estimation method I used is to observe the aggregate impact but separately on men and women. As a first step, I matched people from both categories with the same age, race, education degree and major. Then using the weighted approach, I ran a regression to find out the impact of being self-employed on income levels. Findings from this regression are reported in Table 5A. Male entrepreneurs are found to earn 10,003 USD more on a yearly basis compared to the salary workers with the same characteristics. On the opposite, the female seem to do worse when they are self-employed. The earnings of the self-employed women are on average 5,117 USD less than what they would have been paid had they been an employee. The coefficients are statistically significant.

Table 5A: Matching Estimator Analysis of Income: The Weighted Approach

\begin{tabular}{lll}
\hline Variable & Male & Female \\
\hline $\begin{array}{l}\text { Self-Employment } \\
(=1 \text { if self-employed) } \\
\text { Constant }\end{array}$ & $10003.4(1764.4)$ & $-5117.9(1023.9)$ \\
\hline
\end{tabular}

The second estimation basically uses the following formula:

$$
\Delta_{\mathrm{i}}=\mathrm{Y}_{1 \mathrm{i}}-\mathrm{E}\left(\mathrm{Y}_{0 \mathrm{i}}\right) \text {, }
$$


where $Y_{1 \mathrm{i}}$ is the income that the self-employed individual receives and $E\left(Y_{0 \mathrm{i}}\right)$ is the estimate of the counterfactual. The purpose of this estimation is calculating the estimated impact of treatment $\left(\Delta_{\mathrm{i}}\right)$ on separate age, race and education groups. I also compared the effect on people with different marital as well as rural/urban residence status. Estimations which basically show the means of the estimated treatment impact on the treated are presented in Table 5B.

Table 5B: Matching Estimator Analysis of Income: Estimated Mean Impact of Self-employment

\begin{tabular}{lll}
\hline Variable & Male & Female \\
\hline RACE & & \\
White & $14812.99(100643)$ & $-12093.5(36583.1)$ \\
Black & $10740.1(61280.4)$ & $-4551.9(39278.9)$ \\
Hispanic & $67228.1(106113)$ & $-2874.3(29941.4)$ \\
Asian & $26927.1(94653.1)$ & $2478.9(86551.6)$ \\
DEGREE & & \\
Bachelor's & $8505.7(81788.9)$ & $-10883.3(30375.2)$ \\
Master`s & $16901.8(118024)$ & $-11248.8(29248.8)$ \\
Professional & $24865.7(115678)$ & $-13776(76036.7)$ \\
PhD & $38170.2(145374.8)$ & $-18392.5(41720)$ \\
AGE & & \\
$<35$ & $12956.7(85963)$ & $-10954(21285.2)$ \\
$>=35$ and $<45$ & $18826.8(90251.5)$ & $-9581.2(43617.9)$ \\
$>=45$ and $<60$ & $14346.3(118297)$ & $-29101.9(44091.8)$ \\
$>=60$ & $5819.2(92968.9)$ & \\
MARRIAGE & & $-13760.9(36592)$ \\
Married & $18541.9(103517.5)$ & $-5499(44602.8)$ \\
Single & $-569.9(79309.4)$ & $-10492.1(40139.2)$ \\
RURAL AREA & & $-13825.9(36554.9)$ \\
Urban & $21015.6(103879)$ & \\
Rural & $3581.9(90522.9)$ &
\end{tabular}

The impact of being self-employed is positive on male earnings for each race category. Asian men are found to do much better compare to black and white entrepreneurs. The estimated gap between the income levels of male Asian entrepreneurs and employees is around 27,000 USD per year. As for the female self-employed, the mean impact is negative for all races except for the Asians implying that women are mostly better off when they are wage workers. The sign of the coefficient on the Asian women is quite opposite to what is found in the Heckit analysis. The matching estimator results on both sexes indicate the relative success of Asian people when they choose self-employment. When the average treatment effect is checked in terms of education levels, it is observed that men with professional or $\mathrm{PhD}$ degrees tend to have much higher incomes once they are self-employed. A male entrepreneur with a doctoral degree has a yearly income that is 38,170 USD higher than that of a male salary worker in his matched group. The same gap for a man with a professional degree is 24,865 USD. Female entrepreneurs show a different pattern, though. The mean impact is negative for all educational subgroups and as opposed to men; women do worse when they are self-employed and have a higher degree. This finding matches what the results from the Heckit analysis yield on female entrepreneurs. The estimations on different age categories indicate that middle aged men do better in terms of self-employment income. However, at all age levels, male self-employment earnings are higher than male wages. Being self-employed affects women in all age groups adversely but the category which has the lowest average self-employment income compared to salaries belongs to women who are 60 years of age or older. Being a "married" male entrepreneur is found to bring an extra 18,541 USD on average whereas being a single man is associated with higher wage employment earnings. As for women, wage workers do better regardless of the marital status. However, entrepreneurial income for a married woman is much lower than that of a single woman. Another factor examined in analyzing the difference in income levels is the status of rural residence. Estimation results show that self-employed men have much higher incomes if they are located in an urban area. Whether they are in a rural area or not, female entrepreneurs make much less than they would if they'd been an employee. However, it is important to note that this difference becomes greater if the individual is located in a rural area. The considerable size of the standard deviations obtained from the matching estimator analysis signals the existence of great degree of heterogeneity. So I believe that the use of the matching technique in this study yields more reliable results. 


\section{Conclusion}

Literature of economics provides ample evidence regarding the important positive effect of human capital on earnings. However, the self-employed are consistently omitted in those studies. The papers that are interested in entrepreneurial income focus solely on the comparison of earnings between employees and the self-employed. To my knowledge, there is not any study which examines the role of human capital in determining the entrepreneurial level of earnings. One likely reason for this gap would be data limitations. The NSCG dataset which provides detailed information on majors and degrees helps me deal with this problem and fill the gap in the literature. Regression analyses indicate that male entrepreneurs who completed particular fields of study like architecture, math, physics and chemistry enjoy higher earnings. Returns to self-employment are higher for most engineering majors, too. The main lucrative majors for female self-employment are architecture, medicine, law, psychology and counseling. Once become self-employed, black and younger men seem to earn more. In contrast, older women enjoy higher self-employment earnings. The use of matching estimators yields interesting findings relating the impact of being self-employed on earnings, too. While men do better when they are self-employed, women do the opposite. Asian men and women enjoy higher self-employment incomes compared to people in other race groups. For the male, having higher education, particularly professional and $\mathrm{PhD}$ degrees, leads to being a more successful entrepreneur in terms of income. No particular education level contributes to female entrepreneurial earnings. However, it is found that the female self-employed make worse as they have higher degrees. Another result obtained from the matching analysis is that men in the middle age category get better incomes than those in the other age groups. As for women, the negative effect of being self-employed gets much worse for people who are older than 60. Results show that marriage considerably contributes to male entrepreneurial earnings. Single men are found to be more successful when they are an employee, though. Moreover, being married plays a negative role in women's selfemployment income. Urban residence seems to be a factor affecting the earnings of entrepreneurs positively.

\section{References}

Borjas, G. \& Bronars, S. (1989). Consumer Discrimination and Self-Employment. Journal of Political Economy, 97, 585-605.

Evans, D. S. \& Jovanovic, B. (1989). An Estimated Model of Entrepreneurial Choice Under Liquidity Constraints. Journal of Political Economy, 97(4), 808-27.

Gill, A. (1988). Choice of Employment Status and the Wages of Employees and the Self-employed: Some Further Evidence. Journal of Applied Econometrics, 3, 229-234.

Hamilton, B. (2000). Does Entrepreneurship Pay? An Empirical Analysis of the Returns to SelfEmployment. Journal of Political Economy, 108, 604-631.

Kangasharju, A. \& Pekkala, S. (2001). The Role of Education in Self-employment Success. Growth and Change, 33, $216-237$.

Moore, K. (2004). Comparing the Earnings of Employees and the Self-employed. FEDS Working Paper.

Rees, H. \& Shah, A. (1996). An Empirical Analysis of Self-Employment in the UK. Journal of Applied Economics, 1, 95-108. 